\title{
Causal variants screened by whole exome sequencing in a patient with maternal uniparental isodisomy of chromosome 10 and a complicated phenotype
}

\author{
NIU LI ${ }^{1 *}$, YU DING ${ }^{2 *}$, TINGTING YU ${ }^{1}$, JUAN LI $^{2}$, YONGNIAN SHEN ${ }^{2}$, XIUMIN WANG $^{2}$, \\ QIHUA FU ${ }^{1,3}$, YIPING SHEN ${ }^{1,4}$, XIAODONG HUANG ${ }^{2}$ and JIAN WANG ${ }^{1,3}$ \\ ${ }^{1}$ Institute of Pediatric Translational Medicine; ${ }^{2}$ Department of Endocrinology and Metabolism; \\ ${ }^{3}$ Department of Laboratory Medicine, Shanghai Children's Medical Center, Shanghai Jiaotong University School of Medicine, \\ Shanghai 200127, P.R. China; ${ }^{4}$ Boston Children's Hospital, Boston, MA 02115, USA
}

Received June 7, 2015; Accepted February 11, 2016

DOI: $10.3892 / \mathrm{etm} .2016 .3241$

\begin{abstract}
Uniparental disomy (UPD), which is the abnormal situation in which both copies of a chromosomal pair have been inherited from one parent, may cause clinical abnormalities by affecting genomic imprinting or causing autosomal recessive variation. Whole Exome Sequencing (WES) and chromosomal microarray analysis (CMA) are powerful technologies used to search for underlying causal variants. In the present study, WES was used to screen for candidate causal variants in the genome of a Chinese pediatric patient, who had been shown by CMA to have maternal uniparental isodisomy of chromosome 10. This was associated with numerous severe medical problems, including bilateral deafness, binocular blindness, stunted growth and leukoderma. A total of 13 rare homozygous variants of these genes were identified on chromosome 10. These included a classical splice variant in the HPS1 gene (c.398+5G>A), which causes Hermansky-Pudlak syndrome type 1 and may explain the patient's ocular and dermal disorders. In addition, six likely pathogenic genes on other chromosomes were found to be associated with the subject's ocular and aural disorders by phenotypic analysis. The results of the present study demonstrated that WES and
\end{abstract}

Correspondence to: Professor Xiaodong Huang, Department of Endocrinology and Metabolism, Shanghai Children's Medical Center, Shanghai Jiaotong University School of Medicine, 1678 Dongfang Road, Shanghai 200127, P.R. China

E-mail: jcperkesh@126.com

Professor Jian Wang, Department of Laboratory Medicine, Shanghai Children's Medical Center, Shanghai Jiaotong University School of Medicine, 1678 Dongfang Road, Shanghai 200127, P.R. China

E-mail: labwangjian@shsmu.edu.cn

${ }^{*}$ Contributed equally

Key words: uniparental disomy, whole exome sequencing, chromosomal microarrays analysis, candidate genes, variants
CMA may be successfully combined in order to identify candidate causal genes. Furthermore, a connection between phenotype and genotype was established in this patient.

\section{Introduction}

Uniparental disomy (UPD), which is the abnormal situation in which both copies of a chromosomal pair have been inherited from one parent (1), may affect either a whole chromosome or only part of a chromosome. The latter is termed segmental UPD and has previously been associated with rearrangements in acrocentric chromosomes that frequently occur in Beckwith-Wiedemann syndrome $(2,3)$. Four mechanisms underlie chromosomal UPD formation: i) Trisomy rescue due to trisomic zygote formation resulting from the failure of two homolog chromosomes to segregate into two daughter cells during parental meiosis; ii) Gamete complementation resulting from fertilization between a nullisomic fertilization and a disomic gamete; iii) Monosomy rescue resulting from mitotic endoduplication in a monosomic zygote; and iv) Postfertilization error during postzygotic mitosis $(4,5)$. There are two types of UDP, which are associated with various mechanisms; the first is uniparental heterodisomy, in which the affected chromosome exhibits two different alleles transmitted from the same parent, and the second is uniparental isodisomy (UPiD), in which the affected individual has two copies of the same allele (4).

Since UPD was initially reported in the 1980s (1), studies employing chromosomal microarray analysis (CMA) and whole exome sequencing (WES) technologies have described UPD for nearly every chromosome in the human genome (6,7). CMA is a first-tier clinical diagnostic test that is used to detect genomic copy number variations (CNVs) in patients with developmental disabilities and congenital anomalies (8). Furthermore, CMA permits researchers to identify UPDs in a straightforward manner (8). WES, which is a type of next-generation sequencing technology, is able to efficiently identify genetic defects in patients with sporadic diseases, as well as providing the mutant information of candidate genes involved in UPD (9). Recently, it has been 
demonstrated that WES has the underlying capacity to detect CNVs $(10,11)$. In addition, it may be suitable for detecting UPD (12).

The present study reports the case of a pediatric patient with an undiagnosed and complex medical manifestation who was shown to have UPD at chromosome 10. WES was employed to search for potential causal variants in the patient and to identify connections between candidate genes and the observed phenotypes.

\section{Materials and methods}

Patient. A 20-month-old female infant was referred to the Genetics Department at Shanghai Children's Medical Center, Shanghai Jiaotong University School of Medicine (Shanghai, China) due to multiple severe inborn abnormalities and a severe delay in physiological development after birth (Fig. 1). The patient's mother has had one pregnancy and had delivered a child once, and the child was born at 37 weeks gestation by cesarean delivery due to placental maturation. The patient had an Apgar score (13) of 7'-9' and was comparatively small for her gestational age, with a birth weight of $1,800 \mathrm{~g}$ and a length of $40 \mathrm{~cm}$. The patient's parents were well-educated, not biologically related to each other, and were physically and mentally healthy. The parents claimed that they had not been exposed to any toxic materials. The conception had been natural and the course of the pregnancy uneventful. The patient exhibited feeding difficulties, constipation, severe malnutrition and retardation of growth and development after birth.

A physical examination showed the weight and height of the patient to be $4,200 \mathrm{~g}$ and $50 \mathrm{~cm}$, respectively. The patient's head circumference was $37 \mathrm{~cm}$ and anterior fontanel size was $2 \times 2 \mathrm{~cm}$. The patient had a mild cleft palate, orbital hypertelorism, a long philtrum and blepharophimosis, and was unable to open her right eye. In addition, the patient had dry skin with depigmented spots of various shapes and sizes distributed over her entire body. The patient exhibited no heart murmur, difficultly breathing nor hepatosplenomegaly. She had female-appearing genitalia with a normal urethral opening and a well-proportioned upper and lower body, anus and vaginal opening. Otoacoustic emission, acoustic impedance and brainstem auditory evoked potentials tests demonstrated that the patient had bilateral deafness; corneal light reflex test demonstrated that the patient had binocular blindness. Furthermore, the patient had muscular hypotonia and was unable to raise her head slightly from the prone position. With the exception of crying, the patient was unable to produce any sound.

No unusual results were detected following a laboratory examination involving routine tests of the blood, urine, electrolytes, glucose level and liver, renal and thyroid functions. Neither magnetic resonance imaging (MRI) (Ingenia 1.5T; Philips Healthcare, DA Best, The Netherlands) of the patient's brain, nor screening for inborn metabolic disorders by tandem and gas-chromatography mass spectrometry (micrOTOFI system; Bruker Corporation, Billerica, MA, USA), were able to detect any abnormalities. The study was approved by the ethics committee of Shanghai Children's Medical Center, Shanghai Jiaotong University School of

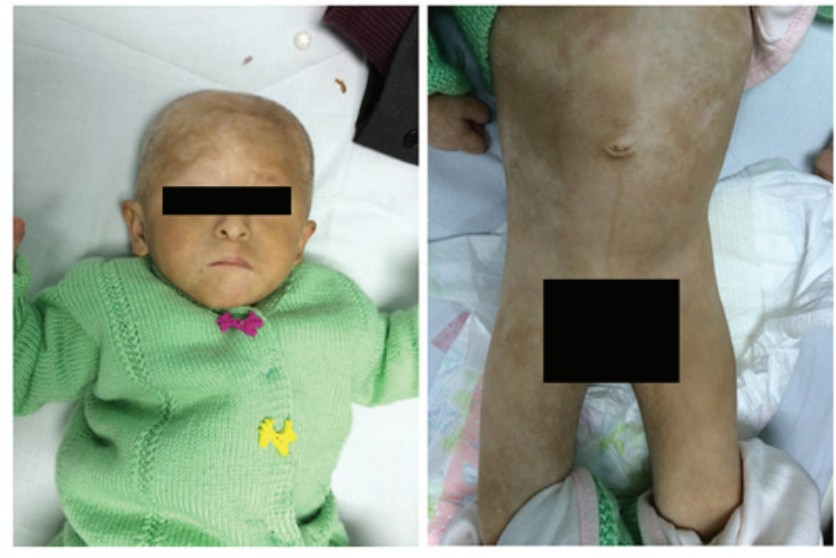

Figure 1. Abnormalities in the patient. The left picture shows the patient's ophthalmic disorder; her right eye was closed and she was unable to open it. Both the left and right pictures show that the patient has sporadic white patches in her skin across her entire body.

Medicine. Written informed consent was obtained from the child's parents.

CMA. The genomic DNA of the patient was isolated from peripheral blood samples $(2 \mathrm{ml})$ using a QIAamp ${ }^{\circledR}$ DNA Blood Mini kit (Qiagen GmbH, Hilden, Germany). Genomic hybridization was conducted using a CytoScan ${ }^{\circledR}$ HD Array kit (Affymetrix, Inc., Santa Clara, CA, USA), according to the manufacturer's protocol. The array is characterized by $>2,600,000 \mathrm{CNV}$ markers, including 750,000 genotype-able single nucleotide polymorphism (SNP) probes and $>1,900,000$ non-polymorphism probes. Data were visualized and analyzed using the Chromosome Analysis Suite (ChAS 3.1; Affymetrix, Inc.) software package with a minimal cut-off of 20 consecutive markers for CNV calling. All reported CNVs were based on the National Center for Biotechnology Information Human Genome Build 37 (hg19) (http://genome.ucsc.edu/cgi-bin/hgGateway).

WES. DNA $(3 \mu \mathrm{g})$ from the patient was sheared to create 150-200 bp fragments using a Covarias M220 Ultrasonicator (Covaris, Woburn, MA, USA). The adapter-ligated library was prepared using a SureSelectXT Human All Exon Kit (Agilent Technologies, Santa Clara, CA, USA) as previously described (14), with coding exons and flanking intronic regions enriched. Subsequently, clusters were generated by isothermal bridge amplification using an Illumina cBot system (Illumina, San Diego, CA, USA), and sequencing was performed with an Illumina HiSeq 2000 system.

A quality assessment of base calling and sequence reads was conducted using an HCS 2.2.58 software (Illumina) and an Illumina HiSeq 2000 system including new versions of HiSeq Control Software and Real-Time Analysis. The alignment of sequence reads to a reference human genome (Human 37.3, SNP135; http://hgdownload.soe.ucsc.edu/goldenPath/hg19/snp135Mask/) was performed using NextGENe ${ }^{\circledR}$ software (version 2.4.1; SoftGenetics, LLC., State College, PA, USA). All single nucleotide variants (SNVs) and indels were saved in a VCF file format, and upladed to the Ingenuity Variant Analysis platform (Qiagen $\mathrm{GmbH}$ ) for biological analysis and interpretation. 


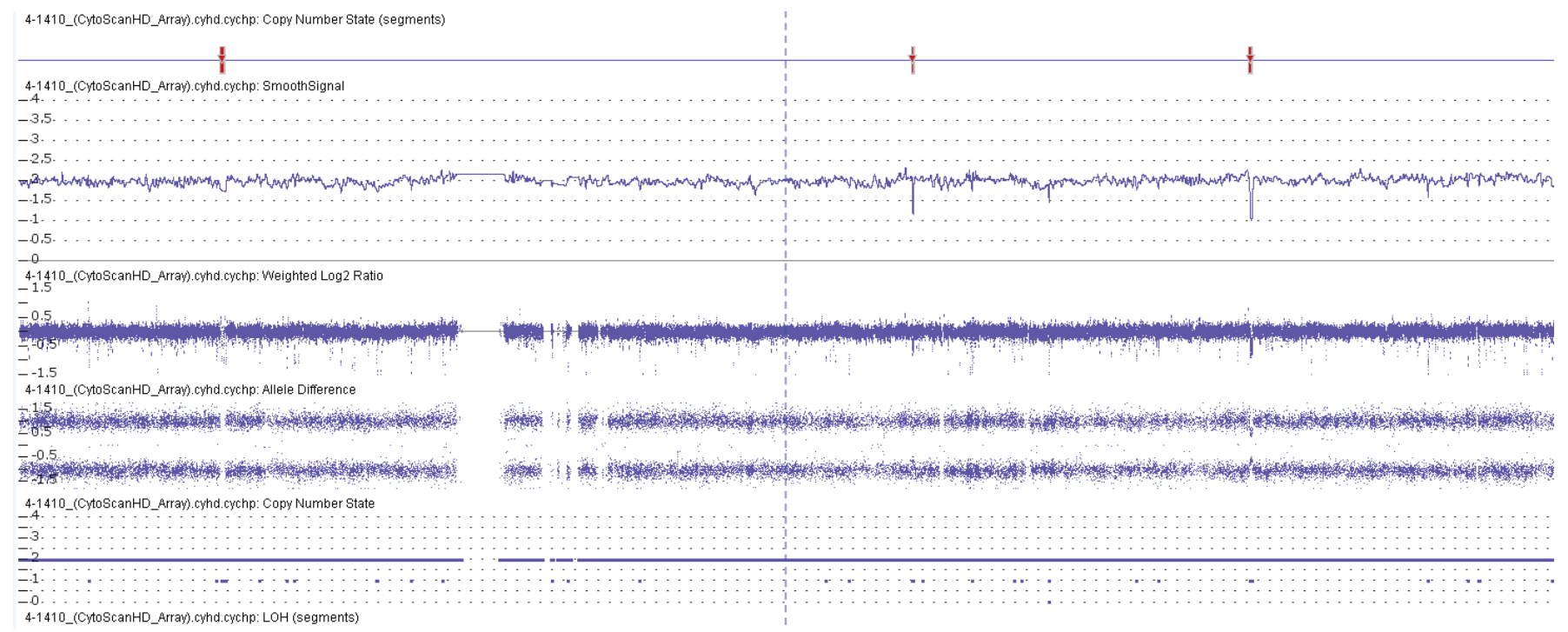

Figure 2. Chromosome microarray analysis results for chromosome 10. Array results showed the copy number state and Log 2 ratio of chromosome 10 to be normal. Conversely, the tracks of allele difference lacked the middle track, which is indicative of whole chromosome loss of heterozygosity ( $\mathrm{LOH})$. $\mathrm{LOH}$ and the absence of copy number variants suggested that the patient had uniparental isodisomy of entire chromosome 10.

In silico analysis. The candidate variants obtained from WES were first screened by the databases of the 1000 Genomes Project (http://www.1000genomes.org/), the National Heart, Lung and Blood Institute Exome Sequencing Project Variant Server (http://evs.gs.washington.edu/EVS/) and the public Complete Genomics (http://www.completegenomics.com/public-data/). Evaluation of the pathogenicity of the candidate variants was performed using the PolyPhen2 online software (http://genetics.bwh.harvard.edu/pph2/).

Sanger sequencing of the Hermansky-Pudlak syndrome 1 (HPS1) gene. Sanger sequencing was performed as previously described (15). The primers for amplification of the HPS1 gene (GenBank accession number, NM_000195.3; http://www.ncbi.nlm.nih.gov/genbank/) were designed using the UCSC ExonPrimer online software (http://genome.ucsc.edu/index.html). The primers for exon 5 were as follows: Forward, 5'-GGCATCTTATCA AACCCGCC-3' and reverse, 5'-ACCAACCAGCTAGAT GACCC-3'. The exons and exon-intron boundaries were amplified by polymerase chain reaction (PCR). The reaction mixture for each amplification contained 1X Premix Taq (Ex Taq version 2.0; RR003; Takara Biotechnology Co., Ltd., Dalian, China), $100 \mathrm{ng}$ genomic DNA and 1 pmol forward and reverse primer in a final volume of $25 \mu \mathrm{l}$. The reaction was performed in the following PCR conditions: Initial denaturation at $95^{\circ} \mathrm{C}$ for $5 \mathrm{~min}$, then 19 cycles of $95^{\circ} \mathrm{C}$ for $30 \mathrm{sec}, 65^{\circ} \mathrm{C}$ for $30 \mathrm{~s}$ and $72^{\circ} \mathrm{C}$ for $45 \mathrm{sec}, 14$ cycles of $95^{\circ} \mathrm{C}$ for $30 \mathrm{sec}, 55^{\circ} \mathrm{C}$ for $30 \mathrm{sec}$ and $72^{\circ} \mathrm{C}$ for $45 \mathrm{sec}$, and a final elongation step at $72^{\circ} \mathrm{C}$ for 5 min using a C1000TM Thermal Cycler (Bio-Rad Laboratories, Inc. Hercules, CA,USA). PCR products were separated by $1 \%$ agarose gel (Sangon Biotechnology Co., Ltd., Shanghai, China) electrophoresis and purified using a QIAquick Gel Extraction kit (Qiagen $\mathrm{GmbH})$. The purified DNA was sequenced using the ABI3730XL sequencer (Applied Biosystems; Thermo Fisher Scientific, Inc., Waltham, MA, USA) with forward and reverse primers. The results were analyzed using a 3730xl DNA Analyzer (Thermo Fisher Scientific, Inc.). The sequence data was analyzed using the Mutation Surveyor DNA Variant Analysis software (version 4.0.4; SoftGenetics, LLC).

\section{Results}

CMA analysis. The CMA analysis using SNP probes suggested that the genome of the patient had a loss of heterozygosity without any CNVs in chromosome 10, which implied that the patient had UPiD of the entire of chromosome 10 (UPiD10) (Fig. 2).

DNA sequencing. The authors of the present study hypothesized that autosomal-recessive variants associated with UPiD10 may have contributed to the clinical manifestations in the patient. Therefore, WES was conducted in order to identify underlying variants. To further characterize chromosome 10, variants in the 1000 Genomes Project, the National Heart, Lung and Blood Institute Exome Sequencing Project Variant Server (http://evs.gs.washington.edu/EVS/) and the public Complete Genomics (http://www.completegenomics. com/public-data/) genomes, were screened for SNPs with a minor allele frequency (MAF) of $<3 \%$. The area of analysis included each exon and 20 bp at exon-intron boundaries. A total of 427 SNVs and 43 indels were shown to meet the filter criteria; these variants covered all chromosomes and the majority were in the heterozygous state (451/470; Table I). For chromosome 10 , there were $13 \mathrm{SNVs}$ present in the homozygous state and no SNVs in the heterozygous state, which was consistent with the results of the CMA. Among these, two candidate genes with intron variations were predicted to be silent and not alter protein translation and expression (PFKFB3, c.873+13C >T; MMS19, c.2776-15G >A).

Among the remaining 11 homozygous variants on chromosome 10 (Table II), the classical splice variant in the HPS1 gene (c.398+5G>A), which results in the skipping of 
Table I. Summary of variants detected by whole exome sequencing (minor allele frequency $<0.03$ ).

\begin{tabular}{lcc}
\hline Parameter & Homozygous (Chr. 10) & Heterozygous \\
\hline Total variants & $19(13)$ & 451 \\
Missense & $14(11)$ & 311 \\
Stop gain & 0 & 9 \\
Frameshift & 0 & 14 \\
Splicing & $1(1)$ & 1 \\
In-frame & 0 & 10 \\
Intron & $4(1)$ & 106 \\
\hline
\end{tabular}

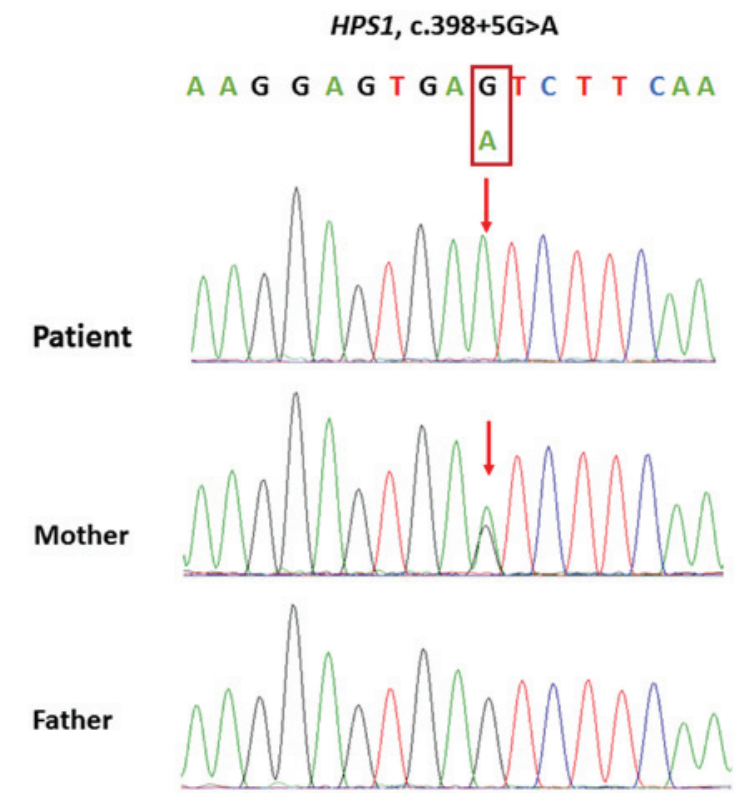

Figure 3. Verification of the c.398+5G $>$ A mutation of the HPS1 gene by Sanger sequencing. Sequencing of the HPS1 gene showed the patient to be homozygous for c. $398+5 \mathrm{G}>\mathrm{A}$, the mother to be heterozygous for the loci, and the father to be homozygous for the wild-type HPS1 gene.

exon 5 in HPS1 mRNA (16), was hypothesized to be associated with the ocular and dermal disorders of the patient. An in-depth analysis of the remaining 10 homozygous variants was conducted, and the results did not show any direct association with the clinical manifestations of the patient. Subsequently, the HPS1 gene in the parents of the patient was evaluated using Sanger sequencing. The sequencing results demonstrated that the patient's mother was heterozygous for c. $398+5 \mathrm{G}>\mathrm{A}$, whereas the patient's father was wild-type (Fig. 3). These results suggested that the patient has maternal UPiD10.

None of the candidate genes could be associated with the deafness of the patient; thus this feature was used to filter the WES results. All symptom-associated SNVs were filtered using the MAF criterion. In addition, they were predicted by the PolyPhen 2 software and compared to the database established by the Department of Laboratory Medicine, Shanghai Children's Medical Center, Shanghai Jiaotong University School of Medicine (containing the WES results of $>200$ Chinese individuals). An autosomal dominant deafness causal gene, $M Y O 1 A$, was shown to have a heterozygous mutation (c.1630C $>$ T, p.R544 W), which PolyPhen2 predicted to be the likely cause of deafness in the patient. Furthermore, an analysis using ocular symptoms identified five heterozygous variants and one homozygous variant (Table III), of which the NR2E3 gene had a heterozygous mutation (c.1127C>T, p.P376L), which may have been associated with the autosomal dominant retinitis pigmentosa and may also have been the cause of the patient's ocular symptoms. The other three candidate genes (NEB, HMX1 and KCNV2) were autosomal recessive, indicating that heterozygous mutations were not the cause of the disease.

\section{Discussion}

The first reported case of a clinical manifestation attributable to UPD was cystic fibrosis, which was caused by maternal UPD of chromosome 7 (17). Numerous pathogenic chromosome UPDs have since been reported, including those of chromosomes 6 , $11,14,15$ and 20 (4). In the majority of cases, the UPD leads to imprinting disorders (ID), where the UPD event involves genomic imprinting, which alters epigenetic regulation and DNA methylation and histone modifications (18). Angelman syndrome is a well known ID [Online Mendelian Inheritance in Man (OMIM), \#105830], which is caused by paternal UPD of chromosome 15 , leading to the lack of expression of the maternally inherited $U B E 3 A$ gene (19). With the exception of IDs, UPDs may cause disease if there is a mutation in a recessive gene, where two identical mutant alleles in the proband are inherited from a heterozygous father or mother. The best example of this is cystic fibrosis, in which the underlying molecular mechanism is the CFTR gene mutation as a result of UPiD7 $(17,20)$.

The present study reports a case of a pediatric patient with UPiD10 associated with numerous severe medical problems, including bilateral deafness, binocular blindness, stunted growth and leukoderma. To the best of our knowledge, such complicated clinical features have not previously been reported in the literature. CMA was used to diagnose the patient with UPiD10. To date, there are only five cases of UPD10 reported in the literature and all UPD10s have been maternal; however, none of the previously described cases have involved genomic imprinting (21-25). The CMA did not reveal any CNVs on chromosome 10; therefore, the authors of the present study predicted that the etiology of the patient may be caused by rare recessive mutations on chromosome 10. Chromosome 10 of the patient was analyzed by WES, and 11 candidate genes were shown to have homozygous variants. Unlike prior studies of UPD10, in the present study, no single candidate gene was able to fully explain the patient's complex clinical manifestations (26).

The HPSI gene encodes a protein that may have a role in the biogenesis of organelles, including melanosomes, platelet dense granules and lysosomes (27). In addition, mutations in HPS1 lead to Hermansky-Pudlak syndrome type 1 (OMIM,\#203300), which is characterized by oculocutaneous albinism, hemorrhagic diathesis, ceroid-lipofuscin accumulation and pulmonary fibrosis $(16,28)$. Thus, this may in part explain the phenotypes associated with the present patient's eyes and skin. A number of the other identified variants, including ITGA8, SEC 31B 


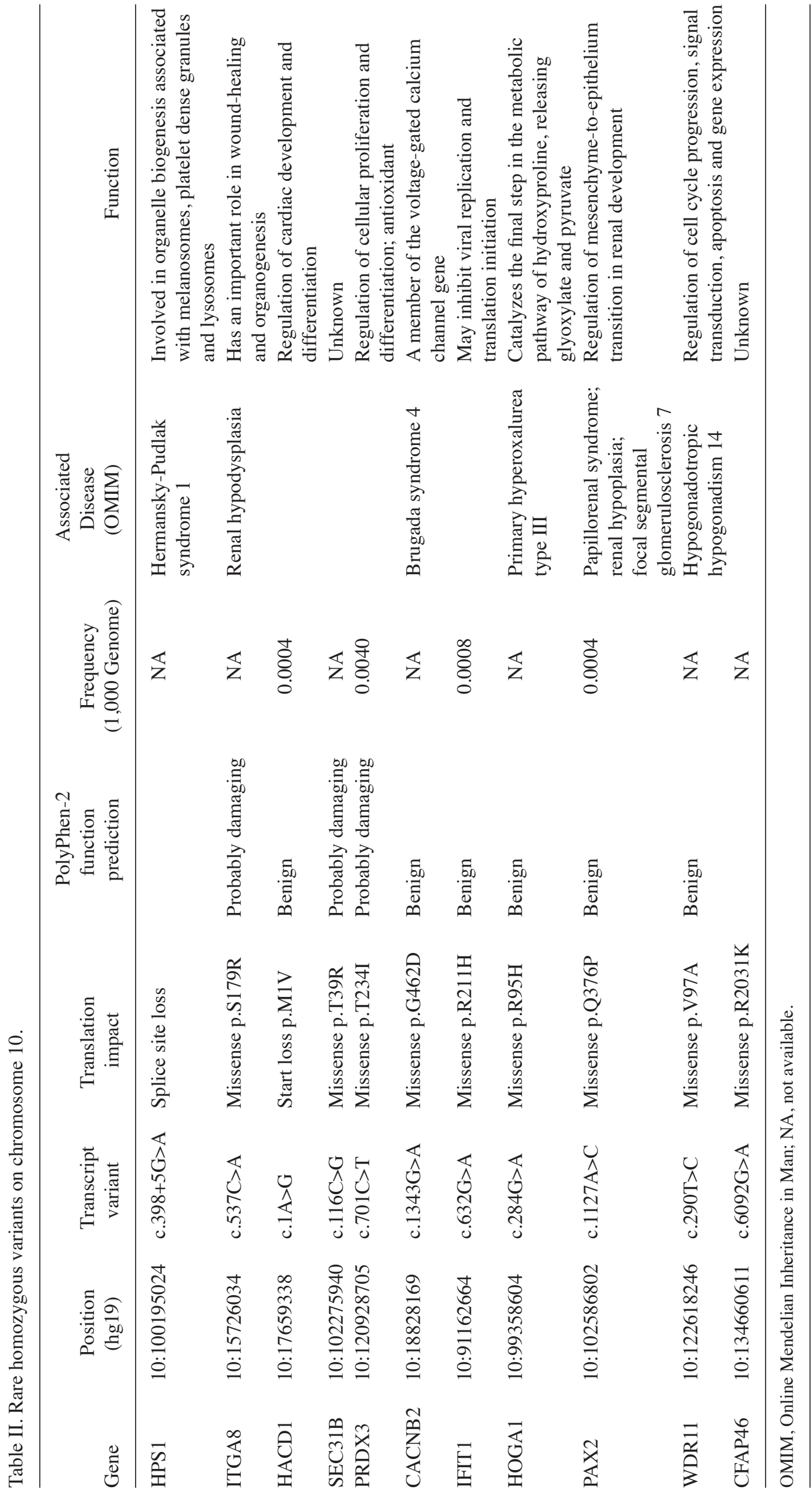


Table III. Probable pathogenic variants associated with the ocular and aural disorders of the patient.

\begin{tabular}{|c|c|c|c|c|c|c|c|}
\hline $\begin{array}{l}\text { Classification } \\
\text { of variants }\end{array}$ & Gene & $\begin{array}{l}\text { Position } \\
\text { (hg19) }\end{array}$ & $\begin{array}{c}\text { Transcript } \\
\text { variant }\end{array}$ & $\begin{array}{l}\text { Translation } \\
\text { impact }\end{array}$ & $\begin{array}{l}\text { Het/ } \\
\text { Hom }\end{array}$ & $\begin{array}{l}\text { Mode of } \\
\text { inheritance }\end{array}$ & $\begin{array}{l}\text { Associated disease } \\
\text { (OMIM) }\end{array}$ \\
\hline \multicolumn{8}{|l|}{ Ocular genes } \\
\hline 1 & $N E B$ & 2:152506779 & c. $7342 \mathrm{C}>\mathrm{T}$ & $\begin{array}{l}\text { Missense } \\
\text { p.R2448C }\end{array}$ & Het & Recessive & Nemaline myopathy 2 \\
\hline 2 & $H M X 1$ & 4:8869775 & c. $691 \mathrm{G}>\mathrm{A}$ & $\begin{array}{l}\text { Missense } \\
\text { p.A231T }\end{array}$ & Het & Recessive & $\begin{array}{l}\text { Oculoauricular } \\
\text { syndrome }\end{array}$ \\
\hline 3 & KCNV2 & $9: 2718925$ & c. $1186 \mathrm{G}>\mathrm{A}$ & $\begin{array}{l}\text { Missense } \\
\text { p.G396R }\end{array}$ & Het & Recessive & $\begin{array}{l}\text { Retinal cone dystrophy } \\
\text { 3B }\end{array}$ \\
\hline 4 & HPS1 & 10:100195024 & c. $398+5 \mathrm{G}>\mathrm{A}$ & $\begin{array}{l}\text { Splice } \\
\text { site loss }\end{array}$ & Hom & Recessive & $\begin{array}{l}\text { Hermansky-pudlak } \\
\text { syndrome type } 1\end{array}$ \\
\hline 5 & NR2E3 & $15: 72109919$ & c. $1127 \mathrm{C}>\mathrm{T}$ & $\begin{array}{l}\text { Missense } \\
\text { p.P376L }\end{array}$ & Het & $\begin{array}{l}\text { Dominant } \\
\text { or recessive }\end{array}$ & $\begin{array}{l}\text { Enhanced S-cone } \\
\text { syndrome; retinitis } \\
\text { pigmentosa } 37\end{array}$ \\
\hline 6 & HPS4 & $22: 26879985$ & c.129_142del & $\begin{array}{l}\text { Frameshift } \\
\text { p.R44fsx10 }\end{array}$ & Het & Recessive & $\begin{array}{l}\text { Hermansky-pudlak } \\
\text { syndrome type } 4\end{array}$ \\
\hline \multicolumn{8}{|l|}{ Aural genes } \\
\hline 1 & MOY1A & $12: 57432326$ & c. $1630 \mathrm{C}>\mathrm{T}$ & p.R544W & Het & Dominant & $\begin{array}{l}\text { Autosomal dominant } \\
\text { deafness }\end{array}$ \\
\hline
\end{tabular}

Het, heterozygous; Hom, homozygous; OMIM, Online Mendelian Inheritance in Man.

and PRDX3, were predicted to be potentially damaging using PolyPhen2 software; however, they could not be associated with the clinical manifestations of the patient. Whether these genes exacerbated symptom caused by the HPS1 gene mutation is unclear and requires further study. Direct sequencing of the HPS1 genes in the parents revealed that the mother had heterozygous loci; thus suggesting that the UPiD10 of the patient was maternal. The authors of the present study hypothesize that UPD10 may always involve a maternal chromosome; however, the underlying mechanism requires further investigation.

In order to improve our understanding of the pathogenesis of the patient, the WES data was filtered using the clinical features, including symptoms of the ears and eyes. Using this strategy, one homozygous variant of the HPS1 gene, and six heterozygous variants located on other chromosomes, were identified. Among these heterozygous variants, the MYOIA gene encodes a member of the myosin superfamily and has a role in actin-based molecular motors (29). Mutations in this gene have previously been associated with autosomal dominant deafness (OMIM, \#607841) (29). The NR2E3 gene encodes a retinal nuclear receptor whose activity is essential to proper rod and cone photoreceptor development and maintenance (30). Defects in this gene are one cause of retinitis pigmentosa 37 (OMIM, \#611131), which is characterized by retinal pigment deposits, rod and cone degeneration and loss of vision (31). Various types of retinitis pigmentosa are autosomal dominant $(31,32)$. Therefore, in the present case, the NR2E3 variant may have a gene dosage effect on the occurrence and development of ocular disorders and may have rendered the illness more complicated.

WES and CMA permit efficient identification of genetic variations. However, they pose significant challenges in terms of data analysis; in particular in the determination of associations between genotypes and complex phenotypes. Despite this, as the use of sequencing technologies and CMA becomes increasingly widespread, the associations between genotypes and phenotypes may become better understood and cases resembling the present report may become more common.

In conclusion, the present study aimed to establish the connection between the patient's phenotype and genotype. The HPS1 gene provided the clearest explanation of this patient's ocular and dermal disorders, while the MOY1A gene may have a role in her deafness and the NR2E3 gene may have exacerbated her ocular symptoms. At present, little is known regarding the functions of several of the candidate genes (CFAP46 and SEC31B), and their roles in the clinical manifestations of the patient remain unclear.

\section{Acknowledgements}

The present study was supported by the National Natural Science Foundation of China (grant nos. 81201353 and 81472051) and the Project of Shanghai Municipal Science and Technology Commission (grant no. 12411950402). The authors of the present study would like to thank the patient and her family for participating in the present study.

\section{References}

1. Engel E: A new genetic concept: Uniparental disomy and its potential effect, isodisomy. Am J Med Genet 6: 137-143, 1980.

2. Kim SR and Shaffer LG: Robertsonian translocations: Mechanisms of formation, aneuploidy, and uniparental disomy and diagnostic considerations. Genet Test 6: 163-168, 2002. 
3. Keren B, Chantot-Bastaraud S, Brioude F, Mach C, Fonteneau E, Azzi S, Depienne C, Brice A, Netchine I, Le Bouc Y, et al: SNP arrays in Beckwith-Wiedemann syndrome: An improved diagnostic strategy. Eur J Med Genet 56: 546-550, 2013.

4. Eggermann T, Soellner L, Buiting K and Kotzot D: Mosaicism and uniparental disomy in prenatal diagnosis. Trends Mol Med 21: $77-87,2015$

5. Grati FR, Grimi B, Frascoli G, Di Meco AM, Liuti R, Milani S, Trotta A, Dulcetti F, Grosso E, Miozzo M, et al: Confirmation of mosaicism and uniparental disomy in amniocytes, after detection of mosaic chromosome abnormalities in chorionic villi. Eur J Hum Genet 14: 282-288, 2006.

6. Yamazawa K, Ogata T and Ferguson-Smith AC: Uniparental disomy and human disease: An overview. Am J Med Genet C Semin Med Genet 154C: 329-334, 2010.

7. Li W, Xia Y, Wang C, Tang YT, Guo W, Li J, Zhao X, Sun Y, Hu J, Zhen $\mathrm{H}$, et al: Identifying human genome-wide $\mathrm{CNV}$, LOH and UPD by targeted sequencing of selected regions. PLoS One 10: e0123081, 2015

8. Miller DT, Adam MP, Aradhya S, Biesecker LG, Brothman AR, Carter NP, Church DM, Crolla JA, Eichler EE, Epstein CJ, et al: Consensus statement: Chromosomal microarray is a first-tier clinical diagnostic test for individuals with developmental disabilities or congenital anomalies. Am J Hum Genet 86: 749-764, 2010

9. Ng SB, Buckingham KJ, Lee C, Bigham AW, Tabor HK, Dent KM, Huff CD, Shannon PT, Jabs EW, Nickerson DA, et al: Exome sequencing identifies the cause of a mendelian disorder. Nat Genet 42: 30-35, 2010.

10. Wang WB, Wang W, Sun W, Crowley JJ and Szatkiewicz JP: Allele-specific copy-number discovery from whole-genome and whole-exome sequencing. Nucleic Acids Res 43:e90, 2015.

11. Tan R, Wang Y, Kleinstein SE, Liu Y, Zhu X, Guo H, Jiang Q, Allen AS and Zhu M: An evaluation of copy number variation detection tools from whole-exome sequencing data. Hum Mutat 35: 899-907, 2014.

12. Martin HC, Kim GE, Pagnamenta AT, Murakami Y, Carvill GL, Meyer E, Copley RR, Rimmer A, Barcia G, Fleming MR, et al: Clinical whole-genome sequencing in severe early-onset epilepsy reveals new genes and improves molecular diagnosis. Hum Mol Genet 23: 3200-3211, 2014 .

13. American Academy of Pediatrics Committee on Fetus and Newborn; American College of Obstetricians and Gynecologists Committee on Obstetric Practice: The Apgar score. Pediatrics. 136: 819-822, 2015

14. Chen R, Im H and Snyder M: Whole-exome enrichment with the agilent SureSelect Human All Exon platform. Cold Spring Harb Protoc 2015: 626-633, 2015.

15. Lee HK, Tang JW, Kong DHL and Koay ES: Simplified large-scale Sanger genome sequencing for influenza A/H3N2 virus. PLoS One 8: e64785, 2013.

16. Oh J, Ho L, Ala-Mello S, Amato D, Armstrong L, Bellucci S, Carakushansky G, Ellis JP, Fong CT, Green JS, et al: Mutation analysis of patients with Hermansky-Pudlak syndrome: A frameshift hot spot in the HPS gene and apparent locus heterogeneity. Am J Hum Genet 62: 593-598, 1998.

17. Spence JE, Perciaccante RG, Greig GM, Willard HF, Ledbetter DH, Hejtmancik JF, Pollack MS, O'Brien WE and Beaudet AL: Uniparental disomy as a mechanism for human genetic disease. Am J Hum Genet 42: 217-226, 1988

18. Girardot M, Feil R and Llères D: Epigenetic deregulation of genomic imprinting in humans: causal mechanisms and clinical implications. Epigenomics 5: 715-728, 2013.
19. Sadikovic B, Fernandes P, Zhang VW, Ward PA, Miloslavskaya I, Rhead W, Rosenbaum R, Gin R, Roa B and Fang P: Mutation Update for UBE3A variants in Angelman syndrome. Hum Mutat 35: 1407-1417, 2014.

20. Le Caignec C, Isidor B, de Pontbriand U, David V, Audrezet MP, Ferec C and David A: Third case of paternal isodisomy for chromosome 7 with cystic fibrosis: A new patient presenting with normal growth. Am J Med Genet A 143A: 2696-2699, 2007.

21. Nogueira C, Marques JS, Nesti C, Azevedo L, Di Lullo M, Meschini MC, Orlacchio A, Santorelli FM and Vilarinho L: Identification of maternal uniparental isodisomy of chromosome 10 in a patient with mitochondrial DNA depletion syndrome. Mol Genet Metab 110: 493-494, 2013.

22. Al-Jasmi F, Abdelhaleem M, Stockley T, Lee KS and Clarke JT: Novel mutation of the perforin gene and maternal uniparental disomy 10 in a patient with familial hemophagocytic lymphohistiocytosis. J Pediatr Hematol Oncol 30: 621-624, 2008.

23. Hahnemann JM, Nir M, Friberg M, Engel U and Bugge M: Trisomy 10 mosaicism and maternal uniparental disomy 10 in a liveborn infant with severe congenital malformations. Am J Med Genet A 138A: 150-154, 2005.

24. Schlegel M, Baumer A, Riegel M, Wiedemann U and Schinzel A: Maternal uniparental isodisomy 10 and mosaicism for an additional marker chromosome derived from the paternal chromosome 10 in a fetus. Prenat Diagn 22: 418-421, 2002

25. Jones C, Booth C, Rita D, Jazmines L, Spiro R, McCulloch B, McCaskill $C$ and Shaffer LG: Identification of a case of maternal uniparental disomy of chromosome 10 associated with confined placental mosaicism. Prenat Diagn 15: 843-848, 1995.

26. Kotzot D and Utermann G: Uniparental disomy (UPD) other than 15: Phenotypes and bibliography updated. Am J Med Genet A 136: 287-305, 2005.

27. Carmona-Rivera C, Simeonov DR, Cardillo ND, Gahl WA and Cadilla CL: A divalent interaction between HPS1 and HPS4 is required for the formation of the biogenesis of lysosome-related organelle complex-3 (BLOC-3). Biochim Biophys Acta 1833: 468-478, 2013.

28. Carmona-Rivera C, Hess RA, O'Brien K, Golas G, Tsilou E, White JG, Gahl WA and Huizing M: Novel mutations in the HPS1 gene among Puerto Rican patients. Clin Genet 79: 561-567, 2011

29. Eisenberger T, Di Donato N, Baig SM, Neuhaus C, Beyer A, Decker E, Mürbe D, Decker C, Bergmann C and Bolz HJ: Targeted and genomewide NGS data disqualify mutations in MYO1A, the 'DFNA48 gene', as a cause of deafness. Hum Mutat 35: 565-570, 2014.

30. Cheng H, Khanna H, Oh EC, Hicks D, Mitton KP and Swaroop A: Photoreceptor-specific nuclear receptor NR2E3 functions as a transcriptional activator in rod photoreceptors. Hum Mol Genet 13: 1563-1575, 2004

31. Coppieters F, Leroy BP, Beysen D, Hellemans J, De Bosscher K, Haegeman G, Robberecht K, Wuyts W, Coucke PJ and De Baere E: Recurrent mutation in the first zinc finger of the orphan nuclear receptor NR2E3 causes autosomal dominant retinitis pigmentosa. Am J Hum Genet 81: 147-157, 2007.

32. Milam AH, Rose L, Cideciyan AV, Barakat MR, Tang WX, Gupta N, Aleman TS, Wright AF, Stone EM, Sheffield VC and Jacobson SG: The nuclear receptor NR2E3 plays a role in human retinal photoreceptor differentiation and degeneration. Proc Natl Acad Sci USA 99: 473-478, 2002. 